\title{
Single-Digit Inflation Targeting and Economic Growth
}

\author{
Richard Ayisi \\ Department of Banking and Finance, Faculty of Accounting and Finance, \\ University of Professional Studies, Accra, Box LG149, Legon-Accra, Ghana
}

Received 2013-08-13, Revised 2013-08-22; Accepted 2013-08-26

\begin{abstract}
In recent times, most central banks have adopted inflation-targeting monetary policy approach aimed primarily to achieve single-digit inflation. Though, the literature suggest that low level of inflation promotes economic growth, the literature is silent on the threshold inflation level needed to promote growth. Studies in developing countries that seek to estimate the threshold level of inflation that promotes economic growth do not support single-digit inflation level. The question that arises is whether single-digit inflation support economic growth. The study thus investigate whether single-digit inflation has any positive effect on economic growth and whether inflation-targeting policy promotes economic growth. The study used annual time series data spanning from 1965 to 2011 for Ghana. Using autoregressive distributed lag model technique, the study found that single-digit inflation has no significant effect on economic growth both in the short and long run. However, the findings of the study supports inflation targeting policy as growth enhancing tool in both short and long run.
\end{abstract}

Keywords: Inflation, Ghana, Economic Growth, ARDL

\section{INTRODUCTION}

In recent times, most central banks across the world have employ inflation targeting monetary policy approach that aim primarily to achieve single-digit inflation. High level of inflation is seen as detrimental to economic growth. As pointed out by Bruno and Easterly (1998), single-digit inflation is important for longer-term economic growth. Following this assertion, monetary policies across countries are geared towards achieving low level of inflation suitable for economic growth.

However, there exist mixed reports from various empirical studies that determined the inflation threshold necessary for economic growth. Khan and Senhadji (2001) estimated between 11-12 inflation rate beyond which inflation significantly affects economic growth negatively for developing countries. While as inflation rate between $1-3 \%$ was estimated for developed or industrialized economies (Hasanov, 2011) estimated 13\% for Azerbaijani. Ahortor et al. (2012); Frimpong and Oteng-Abayie (2010); Quaerty (2010); Munir and
Mansur (2009); Hussain (2005); Burdekin et al. (2000); Gillman et al. (2002); Ghosh and Phillips (1998); Easterly (1998); Sarel (1996) and Fischer (1983). The mixed reports on estimated inflation threshold necessitate a study to investigate whether single-digit inflation is growth enhancing in developing economies, thus giving rise to this study.

Ghana for the past decade has employed inflation targeting as a monetary policy tool to achieve single-digit inflation. However, the estimated inflation threshold for Ghana is beyond single-digit rate (Ahortor et al., 2012; Frimpong and Oteng-Abayie, 2010; Quaerty, 2010) (There is no consensus among the existing literatures on the actual threshold level for Ghana. Available studies provide mixed findings, though they all do not estimate below 11\%). Since available literature did not estimate single-digit inflation threshold for Ghana, it is imperative to investigate whether the single-digit inflation policy in Ghana promotes economic growth. This study is design to fill the knowledge gap by examining the relationship between single-digit 
inflation rates and economic growth with time-series data from Ghana. The objective of the study is twofold. First, the study will investigate whether single-digit inflation promotes economic growth? Secondly, the study will investigate whether the inflation targeting approach adopted in Ghana is growth enhancing.

\subsection{Empirical Studies}

Various studies exist for the growth-inflation node around the world, which indicate the relationship between single-digit inflation and economic growth. These studies are conducted for both developed and developing economies to show the threshold level of inflation that is growth enhancing.

Khan and Senhadji (2001) developed a model to estimate the threshold level of inflation beyond which growth is adversely affected. Testing the model for some economies, Khan and Senhadji (2001) reported a threshold level of inflation above which inflation significantly impede growth as $11-12 \%$ (Various individual country studies have confirmed this findings. Frimpong and Oteng-Abayie (2010) and Ahortor et al. (2012) for Ghana, Mubarik (2005) for Pakistan) for developing countries and $1-3 \%$ for developed countries. Impliedly, the study suggests that inflation rates below 11 and 3\% promote economic growth in developing and developed countries respectively.

The assertion of single-digit inflation threshold has begot further studies, which aim to investigate the relationship between inflation and economic growth. However, irrespective of the time span or scope (whether cross country or country specific analysis), the findings from these studies are mixed. Whiles some studies allude to a positive relationship between economic growth and single-digit inflation, others specify a negative relationship.

In the context of cross country analysis, Gillman et al. (2002) used a panel data of Organization for Economic Cooperation and Development (OECD) and Asia-Pacific Economic Cooperation (APEC) countries and found that reduction of high and medium inflation (double digits) to moderate single digit figures has a significant positive effect on growth for the OECD countries and to a lesser extent for the APEC countries. Also, Kremer et al. (2009) investigated the effect of inflation on long-term economic growth for a panel of 63 industrial and non-industrial countries. The study found that below certain thresholds, the effects of inflation on growth are significantly positive. That is inflation impedes growth if it exceeds thresholds of $2 \%$ for industrial countries and $12 \%$ for non-industrial countries.

In the same regards, Espinoza et al. (2010) used panel data from 165 countries including oil exporting countries as well as Azerbaijan to examine threshold effect of inflation on GDP growth and provide evidence of single-digit inflation promoting growth. Using a smooth transition model over the period of 1960-2007, the study showed that all country groups threshold level of inflation for GDP growth is about $10 \%$ (except for advanced countries where threshold is much lower).

Contrary to the above, other cross country studies suggest that inflation does not always promote economic growth. Sarel (1996) cited in Adusei (2012) reports evidence of a significant structural break at an annual inflation rate of $8 \%$. Below that rate, inflation does not have a significant effect on growth, or it may even show a slightly positive effect. For inflation rates greater than $8 \%$, the effect is negative, statistically significant and strong (Sarel, 1996).

Ghosh and Phillips (1998) allowed for a nonlinear specification in a panel estimation and found that inflation and growth are positively correlated at a very low inflation rates of between $2-3 \%$ a year. However, inflation rate above 3\% adversely affect growth. Also, Burdekin et al. (2000) used a nonlinear growth-inflation specification through a spline estimation technique to estimate different threshold effect among developed and developing countries. The study reports that the turning point for inflation to negatively affect growth is $8 \%$ for developed economies and 3\% for developing economies.

Some studies on growth-inflation nexus that exist for individual countries also confirm mixed results. For example Mubarik (2005) used annual dataset from 1973 to 2000 and report $9 \%$ threshold level of inflation above which inflation is inimical for economic growth. Hussain (2005) for Pakistan, Munir and Mansur (2009) for Malaysia.

Studies from Africa further confirm the above mixed findings. Phiri (2010) investigated the level of inflation which is least detrimental towards finance -growth activity for the South African economy. The study estimated an inflation threshold in a nonlinear finance-growth regression for quarterly data collected between the period February 2000 and July 2010 and reported that (1) inflation has an adverse effect on finance-growth activity at all levels of inflation and (2) the least adverse effects of inflation on finance-growth activity are established at an inflation level of $8 \%$. Above and below this level, according to Phiri (2010), real activity losses gradually begin to be magnified the further one moves from the threshold. 
The foregoing discussions indicate mixed results on the level of inflation threshold that promote economic growth. Regardless of this, most countries' monetary policies aim at single-digit inflation through the inflation-targeting approach. However, is the single-digit inflation growth enhancing? This has resulted in studies to investigate whether single-digit inflation promote economic growth. The notable study is Adusei (2012), which investigated whether singledigit inflation promotes economic growth with annual time series data from South Africa for the period 19652010. The findings of the study suggests that singledigit inflation undermines economic growth in the long run. Thus, the study suggested that inflation targeting in the single-digit threshold may not be in the best interest of a developing economy like South Africa.

Nevertheless, Ghana has practiced inflationtargeting to achieve single-digit inflation for the past decade. However, available literature on Ghana provides mixed findings about the level of inflation threshold (Frimpong and Oteng-Abayie, 2010; Quaerty, 2010; Ahortor et al., 2012). Thus, it is imperative to investigate whether this phenomena supports economic growth in Ghana. Since no literature (This is per the coverage of literature available within the study period) exist in this regard for Ghana, this study comes in handy to address this gap in literature.

\section{MATERIALS AND METHODS}

\subsection{Theoretical Framework}

The study estimates a growth-inflation relationship to investigate the effect of inflation on economic growth. The growth-inflation relationship is explained using the Keynesian aggregate demand and aggregate supply framework. In this framework, aggregate demand curve is derived as a locus of points showing the price-output combination that ensures internal equilibrium. The internal equilibrium is obtained from the simultaneously equilibrium of both the goods and money market.

Assuming a flexible price situation, the goods and money market equilibrium situations are represented by the IS and LM given respectively as:

$$
\begin{aligned}
& \text { IS }: r=A \propto\left(\frac{Y}{P}\right) \\
& L M: r=\beta_{0}\left(\frac{M}{P}\right)+\beta_{1}\left(\frac{Y}{P}\right)
\end{aligned}
$$

Where:

$\propto=\beta_{0}, \beta_{1}>0$

$\mathrm{A}=$ Set of autonomous or exogenous variables

$\mathrm{M}=$ Domestic Credit

$\mathrm{Y}=$ Output level

$\mathrm{P}=$ General Price level

The solutions of Equation (1) and (2) yield:

$$
\left(\frac{\mathrm{Y}}{\mathrm{P}}\right)=\varnothing \mathrm{A}-\delta\left(\frac{\mathrm{M}}{\mathrm{p}}\right)
$$

Where:

$$
\begin{aligned}
& \varnothing=\frac{1}{\propto+\beta_{1}} \\
& \delta=\frac{\beta_{0}}{\propto+\beta_{1}}
\end{aligned}
$$

Given that all the variables except A in Equation (3) is time dependent, then taking the logarithm of the variables and differentiating them with respect to time results in growth term expressed as:

$\mathrm{y}-\pi=\varnothing \mathrm{A}-\delta(\mathrm{m}-\pi)$

Where:

$$
\mathrm{y}=\frac{1}{\mathrm{Y}} * \frac{\mathrm{dy}}{\mathrm{dt}}, \mathrm{m}=\frac{1}{\mathrm{M}} * \frac{\mathrm{dm}}{\mathrm{dt}}, \pi=\frac{1}{\mathrm{P}} * \frac{\mathrm{dp}}{\mathrm{dt}}
$$

Re-arranging Equation (4) gives:

$\mathrm{y}=\varnothing \mathrm{A}-\delta \mathrm{m}+(1+\delta) \pi$

Equation (5) postulates a positive relationship between economic growth and inflation. However, using the aggregate supply framework (The aggregate supply curve is derived using the Phillips curve and Okun's law in the labor market wage determination) to derive the price-output relationship, the framework shows that though inflation positively affect growth, if the prevailing inflation rate is below expected then the relationship will be negative.

From the aforementioned, an empirical model specification showing the relationship between growth and inflation is given as: 
GROWTH $=\rho_{0}+\rho_{1}$ INFLATION $+\nexists Z+\varepsilon$

where, $\mathrm{Z}$ is a vector of explanatory variables.

\subsection{Econometric Modelling}

Following Equation (6), the study modelleda growth-inflation relations, which specified a relationship between per capita GDP (YPN), inflation and other plausible explanatory variables of growth. The explanatory variables include credit to private sector as share of GDP (CPS) and broad money supply as share of GDP (BM), which are used as proxies for the degree of intermediary services and overall size of the financial intermediary sector respectively (Saci et al., 2009). Final government Consumption Expenditure (GC) is used as a proxy for the size of government in the economy (Shahbaz, 2009). The openness (E) of the economy is proxy by the ratios of exports and imports to GDP (King and Levine, 1993; Ghosh and Phillips, 1998; Zang and Kim, 2007; Saci et al., 2009). Population growth is also included since it is an important determinant of growth from the Solow growth theory.

The empirical models estimated are given as:

\section{MODEL 1}

$\mathrm{YPN}_{\mathrm{t}}=\mathrm{a}_{0}+\mathrm{a}_{1}$ DINFL $_{\mathrm{t}}+\mathrm{a}_{2} \mathrm{BM}_{\mathrm{t}}$

$+\mathrm{a}_{3} \mathrm{GC}_{\mathrm{t}}+\mathrm{a}_{4} \mathrm{CPS}_{\mathrm{t}}+\mathrm{a}_{5} \mathrm{E}_{\mathrm{t}}+\mathrm{a}_{6} \mathrm{LN}(\mathrm{POP})_{\mathrm{t}}+\varepsilon_{\mathrm{t}}$

\section{MODEL 2}

$$
\begin{aligned}
& \text { YPN }_{t}=b_{0}+b_{1} \text { DINFL 2 }_{t}+b_{2} \text { BM }_{t} \\
& +b_{3} G_{t}+b_{4} \text { CPS }_{t}+b_{5} E_{t}+b_{6} \operatorname{LN}(\text { POP })_{t}+\mu_{t}
\end{aligned}
$$

The study estimated the two models above, each incorporating the study's objective. To capture the objective of the study, inflation is included in the model as a dummy. To capture the first objective of the effect of single-digit inflation on growth, a dummy of inflation is created to take the value of 1 in years when single-digit inflation is recorded and 0 in years when double-digit inflation are recorded. This effect is incorporate in model (1). Regarding the second objective to determine the effect of inflation-targeting policy on growth, a dummy of inflation is created as 1 for periods of inflation-targeting and 0 for non-inflation targeting periods. This effect is incorporated in model (2).

The study employed Autoregressive Distributed Lag (ARDL) model developed by Persaran to estimate
Equation $7 \mathrm{a}$ and $7 \mathrm{~b}$. The ARDL modelling technique was favoured because of the flexibility that it can be applied when the variables are of different order of integration (Pesaran and Pesaran, 1997). Also, the approach allows the model takes sufficient numbers of lags to capture the data generating process in a generalto-specific modelling framework (Laurenceson and Chai, 2003). Moreover, a dynamic Error Correction Model (ECM) can be derived from ARDL through a simple linear transformation (Banerjee et al., 1986). The ECM integrates the short-run dynamics with the long-run equilibrium without losing long-run information. It is also argued that using the ARDL approach avoids problems resulting from nonstationary time series data (Laurenceson and Chai, 2003). Finally, this technique is suitable for small or finite sample size (Pesaran et al., 2001).

\subsection{Estimation Results}

\subsubsection{Unit Root Test}

Table 1 presents the unit root test of the series using both ADF and KPSS tests. The ADF test indicates that all the series are I (1) except log of population which is stationary at level. Contrary, KPSS results showed that all the series are stationary at level. However, since ADF is noted for its low power and size test, the study followed results of KPSS indicating that all the series are stationary at levels.

Table 1. Unit root test

\begin{tabular}{llll}
\hline & ADF TEST & & \\
& - & & \\
& Level & KPSS TEST \\
Series & T-ratio & T-Ratio & $\begin{array}{l}\text { Level } \\
\text { T-ratio }\end{array}$ \\
\hline YPN & 2.7858 & -4.4049 & 0.5324 \\
& $(1.0000)$ & $(0.001)^{* * *}$ & \\
BM & -1.2196 & -6.7826 & 0.3088 \\
& $(0.6581)$ & $(0.000)^{* * *}$ & \\
GC & -2.4982 & -6.4386 & 0.2289 \\
& $(0.1225)$ & $(0.000)^{* * *}$ & \\
CPS & -0.7491 & -7.4289 & 0.4389 \\
& $(0.8237)$ & $(0.000)^{* * *}$ & \\
E & 3.2188 & -3.616 & 0.7763 \\
& $(1.0000)$ & $(0.009)^{* * *}$ & \\
LOG(N) & -3.3837 & -2.5477 & 0.1083 \\
& $(0.0687)^{*}$ & $(0.305)$ & \\
\hline The asympt
\end{tabular}

The asymptotic critical values for KPSS are $1 \%(0.21600), 5 \%$ $(0.14600)$ and $10 \%(0.11900)$ for estimation with both trend and intercept and $1 \%(0.739), 5 \%(0.463)$ and $10 \%(0.347)$ for estimation with only intercept. For ADF, value in parenthesis is the p-value, which is compared to $5 \%$. Source: Estimates from E-views 


\section{RESULTS}

The study employed the ARDL technique and its reparameterisation into error correction model to estimate Equation $7 \mathrm{a}$ and $7 \mathrm{~b}$. In both estimation, the optimal model is selected on the basis of the prediction power by either the Schwartz-Bayesian Criteria (SBC) or Akaike Information Criteria (AIC) (The prediction power is obtained by comparing the prediction errors of the models. The information criteria for model selection are a function of the residual sums of squares and are asymptotically equivalent).

The appropriate model was selected based on the Schwartz-Bayesian criteria, since it provided the model with higher prediction power. Table 3A, B and 4A, B below present the short and long run estimation results for model (1) and model (2) respectively.

To ascertain the viability of the model, a diagnostic test was conducted. The tests indicate that the selected model is satisfactory. The adjusted R-squared is given as 0.97908 and 0.98306 for Equation $7 \mathrm{a}$ and $7 \mathrm{~b}$ respectively. The high R-squared for both ARDL models show that the overall goodness of fit of the model is satisfactory. The Fstatistic measuring the joint significance of all the regressors in the model are statistically significant at $1 \%$ for both models. Similarly, the Dubin-Watson statistics for both models approximate 2 .

The diagnostic test results show that both models pass the tests for functional form, normality, serial correlation and homoscedasticity. Table 2 provide the diagnostic test for both model. The plot of the stability test results (CUSUM and CUSUMSQ) of the ARDL model are shown in Fig. 1. The CUSUM and CUSUMSQ plotted against the critical bound of the 5\% significant level show that the model are stable overtime.

Since both ADF and KPSS showed conflicting results about the presence of unit root, the study tested for co-integration to avoid spurious results. The study used the error correction test of co-integration (The error correction based co-integration test, tests for the significance of the coefficient of the error correction term in a dynamic model (Banerjee et al., 1986). If the error correction term is significant then the series are co-integrated). The coefficient of the error correction term in both models are statistically significant at $1 \%$, indicating that the series are co-integrated. Hence inferences can be made from the estimated results.
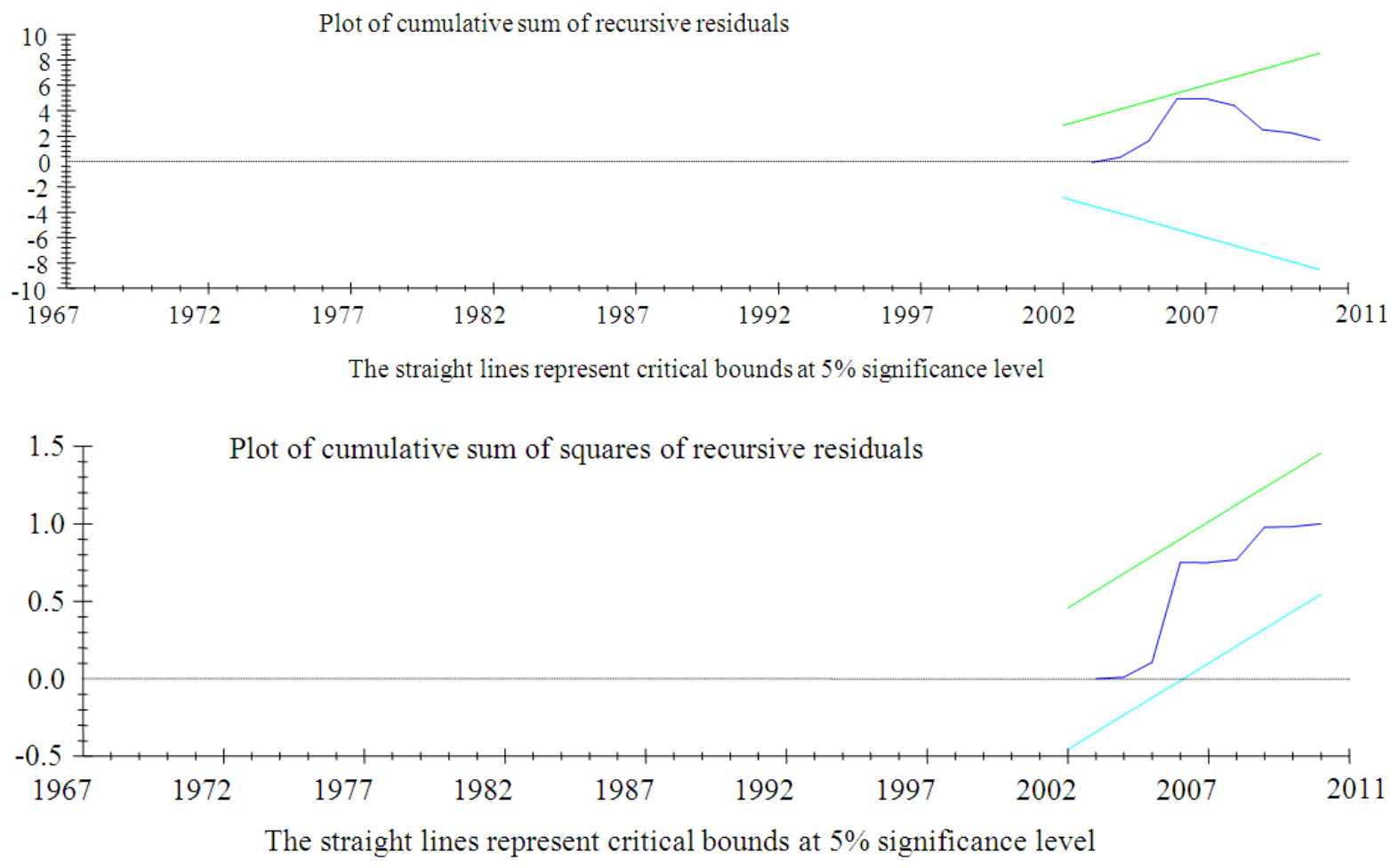

Fig. 1. Graph of CUSUM and CUSUMSQ 
Table 2. Diagnostic test results

\begin{tabular}{lcc}
\hline & Model 1 & Model 2 \\
\hline $\mathrm{R}^{2}$ Adjusted & 0.97908 & 0.98306 \\
F-Statistic & 188.24100 & 233.16700 \\
& $(0.000)^{* * *}$ & $(0.000)^{* * *}$ \\
Dubin-Watson Statistic & 1.82230 & 1.73480 \\
Serial Correlation $\left(\chi^{2}\right)$ & 0.42587 & 0.48084 \\
& $(0.514)$ & $(0.488)$ \\
Functional Form $\left(\chi^{2}\right)$ & 2.61470 & 0.72683 \\
& $(0.106)$ & $(0.394)$ \\
Normality $\left(\chi^{2}\right)$ & 1.04931 & 0.48660 \\
& $(0.592)$ & $(0.784)$ \\
Heteroscedasticity $\left(\chi^{2}\right)$ & 0.16691 & 0.09702 \\
& $(0.683)$ & $(0.755)$ \\
\hline
\end{tabular}

NB: figures in parenthesis represent $p$-values

Table 3A. Short run estimates for model 1

\begin{tabular}{lrrl}
\hline Regressors & Coefficient & T-Ratio & P-value \\
\hline YPN(-1) & 0.74428 & 8.2712 & $0.000^{* * *}$ \\
BM & -12.70730 & -3.5584 & $0.001^{* * *}$ \\
BM(-1) & 7.26750 & 1.6793 & 0.103 \\
BM(-2) & 7.46420 & 2.3064 & $0.028^{* *}$ \\
GC & -6.80900 & -1.4982 & 0.144 \\
CPS & -5.45020 & -1.2909 & 0.206 \\
E & 455.06760 & 7.8351 & $0.000^{* * *}$ \\
E(-1) & -333.14850 & -3.3584 & $0.002^{* * *}$ \\
E(-2) & 145.64200 & 2.1158 & $0.042^{* *}$ \\
LN(POP) & -609.94940 & -3.0572 & $0.004^{* * *}$ \\
DINFL & 41.77900 & -1.3248 & 0.194 \\
INPT & 4336.90000 & 3.0204 & $0.005^{* * *}$ \\
\hline
\end{tabular}

NB: $(*),(* *),(* * *)$ indicates significance level at $10 \%, 5 \%$ and $1 \%$ respectively. Source: Estimates from Micro fit 4.1

Table 3B. Long run estimates for model 1

\begin{tabular}{lrrl}
\hline Regressors & Coefficient & T-Ratio & P-Value \\
\hline BM & 7.9163 & 0.76813 & 0.448 \\
GC & -26.6265 & -1.64710 & 0.109 \\
CPS & -21.3130 & -1.40360 & 0.170 \\
E & 1046.3000 & 6.22690 & $0.000^{* * *}$ \\
LN(POP) & -2385.2000 & -3.91090 & $0.000^{* * *}$ \\
DINFL & -163.3773 & -1.27280 & 0.212 \\
INPT & 16959.6000 & 3.96770 & $0.000^{* * *}$ \\
\hline NB
\end{tabular}

NB: $(*),(* *),(* * *)$ indicates significance level at $10 \%, 5 \%$ and $1 \%$ respectively. Source: Estimates from Micro fit 4.1

Table 4A. Short-run estimates for model 2

\begin{tabular}{lrrl}
\hline Regressors & Coefficient & \multicolumn{1}{c}{ T-Ratio } & P-value \\
\hline YPN(-1) & 0.63488 & 7.08250 & $0.000^{* * *}$ \\
DINFL2 & 112.99000 & 3.14950 & $0.003^{* * *}$ \\
BM & -11.55470 & -3.65480 & $0.001^{* * *}$ \\
BM(-1) & 3.74130 & 0.91971 & 0.364 \\
BM (-2) & 6.45510 & 2.20690 & $0.034^{* *}$ \\
GC & -7.21440 & -1.76770 & $0.086^{*}$ \\
CPS & -11.86710 & -3.04780 & $0.005^{* * *}$ \\
E & 405.38890 & 8.20220 & $0.000^{* * *}$ \\
E(-1) & -273.18840 & -3.02380 & $0.005^{* * *}$ \\
E(-2) & 195.34010 & 3.03650 & $0.005^{* * *}$ \\
LN(POP) & -713.13820 & -4.15620 & $0.000^{* * *}$ \\
INPT & 5164.70000 & 4.13120 & $0.000^{* * *}$ \\
\hline NB: $\left(^{*}\right)(* *)(* * *)$ indicate significance at $10 \%, 5 \%$ and $1 \%$ \\
respectively. Source: Estimates from Micro fit 4.1
\end{tabular}

\begin{tabular}{lrrl}
\multicolumn{6}{l}{ Table 4B. Long-run estimates for model 2 } \\
\hline Regressors & Coefficient & T-Ratio & P-value \\
\hline DINFL2 & 309.4602 & 3.31110 & $0.002^{* * *}$ \\
BM & -3.7201 & -0.56229 & 0.578 \\
GC & -19.7590 & -1.92320 & $0.063^{*}$ \\
CPS & -32.5019 & -3.58580 & $0.001^{* * *}$ \\
OPENNESS & 897.0769 & 9.73070 & $0.000^{* * *}$ \\
LN(POP) & -1953.2000 & -6.63320 & $0.000^{* * *}$ \\
INPT & 14146.1000 & 6.77650 & $0.000^{* * *}$
\end{tabular}

NB: $(*),(* *),(* * *)$ indicates significance level at $10 \%, 5 \%$ and $1 \%$ respectively. Source: Estimates from Micro fit 4.1

\section{DISCUSSION}

The results in Table $\mathbf{3 A}$ and $\mathbf{3 B}$ show that singledigit inflation has no significant relationship with GDP in both short and long runs. This means that the pursuance of single-digit inflation by monetary authorities has no significant impact on the economic growth of Ghana. Contrary to the Bruno and Easterly (1998) study which showed that "getting inflation down to single digit is important even for longer-term growth reasons", the findings of this study indicates that single-digit inflation has no relationship with growth. In the same regards, the study contradict that of Adusei (2012), which found a significant weak negative relationship between single-digit inflation and economic growth for South Africa.

Regarding the second objective of the relationship between economic growth and single-digit inflationtargeting, the study found significant relationship between economic growth and inflation targeting. Table 4A and 4B above provides the result of model estimation capturing this effect. It is evident from the Table 4A and $B$ that inflation-targeting monetary policy is statistically significant both in the short and long runs. Results from Table 4A and $B$ shows that inflationtargeting periods impact positively on economic growth at $1 \%$ significance level both in the short and long run.

\section{CONCLUSION}

The study aimed to investigate two issues: whether single-digit inflation has any positive effect on economic growth and whether inflation-targeting policy adopted by Ghana promotes economic growth. Evidence from the analysis indicates that single-digit inflation has no significant effect on economic growth both in the short and long term. However, inflation targeting policy enhances economic growth both in the short and long run.

Impliedly, the Bank of Ghana can still use inflation targeting policy since it is not detrimental to growth. However, the objective of Bank of Ghana should be to 
stabilise prices rather than aiming single-digit inflation, since there is no significant relationship between economic growth and single-digit inflation.

The study used data from World Development Indicator (WDI) gathered from survey reports by the World Bank (http://www.worldbank.org). Thus, the validity of the study's conclusion is limited to the extent to which these data are credible.

\section{REFERENCES}

Adusei, M., 2012. Single-digit inflation targeting: Does it promote economic growth?. J. Econ. Sustain. Dev., 3: 102-107.

Ahortor, C.R.K., A. Adenenkan and W. Ohemeng, 2012. An Estimate of Inflation Threshold inthe WAMZ: The case of Ghana and Nigeria. WAMIJ, 11: 158-201.

Banerjee, A., J.J. Dolado, D.F. Hendry and G.V. Smith, 1986. Exploring equilibrium relationships in econometrics through static models: Some monte carlo evidence. Bulletin, 48: 253-277.

Bruno, M. and W. Easterly, 1998. Inflation crises and long-run growth. J. Monetary Econ., 41: 3-26. DOI: 10.1016/S0304-3932(97)00063-9

Burdekin, R.C.K., A.T. Denzau, M.W. Keil, T. Sitthiyot and D. Willett, 2000. When does inflation hurt economic growth? different nonlinearities for different economies. Claremont Graduate University.

Easterly, W., 1998. Life during growth. J. Econ. Growth, 4: 239-276. DOI: 10.1023/A:1009882702130

Espinoza, R.A., H.L. Leon and A. Prasad, 2010. Estimating the Inflation-Growth Nexus: A Smooth Transition Model. 1st Edn., International Monetary Fund, ISBN-10: 1451985215, pp: 99.

Fischer, S., 1983. Inflation and Growth. Cambridge, MA.

Frimpong, J.M. and E.F. Oteng-Abayie, 2010. When is inflation harmful? Estimating the threshold effect for Ghana. Am. J. Econ. Bus. Admin., 2: 232-239. DOI: 10.3844/ajebasp.2010.232.239

Ghosh, A. and S. Phillips, 1998. Warning: Inflation may be Harmful to your Growth. Staff Papers Int. Monet. Fund, 45: 672-710.

Gillman, M., M. Harris and M. Laszlo, 2002. Inflation and Growth: Some theory and evidence. Central European University Working Paper.

Hasanov, F., 2011. Relationship between inflation and economic growth in Azerbaijani economy: Is there any threshold effect?. Asian J. Bus. Manage. Sci., 1: 1-11.

Hussain, M., 2005. Inflation and Growth: Estimation of threshold point for Pakistan. Pak. Bus. Rev., 1: 1-15.
Khan, M.S. and A.S. Senhadji, 2001. Threshold effects in the relationship between inflation and growth. IMF Staff Papers, 48: 1-21.

King, R.G. and R. Levine, 1993. Finance and Growth: Schumpeter might be right. Q. J. Econ., 108: 717737.

Kremer, S., A. Bick and D. Nautz, 2009. Inflation and growth: New evidence from a dynamic panel threshold analysis. Freie Universitat Berlin.

Laurenceson, J.J. and C.H. Chai, 2003. Financial Reform and Economic Development in China. 1st Edn., Edward Elgar Publishing, Northampton, MA., ISBN-10: 1843767198, pp: 159.

Mubarik, Y.A., 2005. Inflation and Growth: An estimate of the threshold level of inflation in Pakistan. State Bank Pak. Res. Bull., 1: 35-44.

Munir, Q. and K. Mansur, 2009. Non-linearity between inflation rate and GDP growth in Malaysia. Econ. Bull., 29: 1551-1565.

Pesaran, H.M., Y. Shin and R.J. Smith, 2001. Bounds testing approaches to the analysis of level relationships. J. Applied Econ.., 16: 289-326. DOI: 10.1002/jae.616

Pesaran, M.H. and B. Pesaran, 1997. Working with Microfit 4.0: Interactive Econometric Analysis. 1st Edn., Oxford University Press, ISBN-10: 0192685317, pp: 505.

Phiri, A., 2010. At what level is inflation least detrimental towards finance-growth activity in South Africa? J. Sustain. Dev. Afr., 12: 354-364.

Quaerty, P., 2010. Price stability and the growth maximizing rate of inflation for Ghana. Modern Econ., 1: 180-194. DOI: 10.4236/me.2010.13021

Saci, K., G. Giorgioni and K. Holden, 2009. Does financial development affect growth? Applied Econ., 41: 1701-1707. DOI: 10.1080/00036840701335538

Sarel, M., 1996. Nonlinear effects of inflation on economic Growth. IMF Staff Papers, 43: 199-215. DOI: $10.2307 / 3867357$

Shahbaz, M.A., 2009. A reassessment of finance-growth nexus for Pakistan: Under the investigation of FMOLS and DOLS techniques. IUP J. Applied Econ., 8: 65-80.

Zang, H. and Y.C. Kim, 2007. Does financial development precede growth? Robinson and lucas might be right. Applied Econ. Lett., 14: 15-19. DOI: $10.1080 / 13504850500425469$ 